\title{
Combined administration of antibiotics increases the incidence of antibiotic-associated diarrhea in critically ill patients
}

This article was published in the following Dove Press journal: Infection and Drug Resistance

\author{
Hongye $\mathrm{Ma}^{\mathrm{l}}$ ** \\ Lei Zhang ${ }^{1} *$ \\ Yanshu Zhang ${ }^{1} * *$ \\ Yu Liu' \\ Yingli $\mathrm{He}^{2}$ \\ Litao Guo' \\ 'Department of Critical Care Medicine, \\ The First Affiliated Hospital of Xi'an \\ Jiaotong University, Xi'an, People's \\ Republic of China; ${ }^{2}$ Department of \\ Infectious Diseases, The First Affiliated \\ Hospital of Xi'an Jiaotong University, \\ Xi'an, People's Republic of China \\ *These authors contributed equally to \\ this work
}

Correspondence: Yingli He Department of Infectious Diseases, The First Affiliated Hospital of Xi'an Jiaotong University, Xi'an, People's Republic of China

Email heyingli2000@I63.com

Litao Guo

Department of Critical Care Medicine, The First Affiliated Hospital of Xi'an Jiaotong University, Xi'an, People's Republic of China

Email glt02@I63.com
Background: The widespread use of antibiotics has resulted in a high incidence of antibiotic-associated diarrhea (AAD); moreover, the AAD-associated mortality rates have also increased. The effect of combined antibiotic administration on AAD in critically ill patients was analyzed to assist in antibiotic selection for AAD prevention.

Methods: Clinical data of patients hospitalized were retrospectively analyzed. Patients were either assigned to the combined-use group (CG) or the monotherapy group (MG). Age, sex, albumin levels, proton pump inhibitors, the type antibiotics, occurrence of AAD were collected. All relevant data were analyzed using SPSS version 18.0 (IBM Inc., Armonk, NY, USA), and significance was set at $P<0.05$.

Measurements and main results: Overall, 277 patients were enrolled $(C G, n=143$; MG, $\mathrm{n}=134)$. The incidence of AAD was significantly different between the groups $(44.06 \%$ vs $17.16 \%, P<0.001)$. Combined use of three or more antibiotics, other antibiotics combined with antifungals antibiotics increases the incidence of $\mathrm{AAD}(P<0.05)$. Duration of proton pump inhibitor therapy (odds ratio [OR] 1.142, 95\% confidence interval [CI] 1.048-1.244, $P=0.002$ ), antifungal antibiotic administration (OR 3.189, 95\% CI 1.314-7.740, $P=0.010$ ), and beta-lactam plus enzyme inhibitor antibiotic administration (OR 3.072, 95\% CI 1.309-7.205, $P=0.010$ ) were associated with $\mathrm{AAD}$ in critically ill patients receiving combined antibiotics therapy. The mean duration of intensive care unit admission was longer among patients with AAD compared with patients without AAD $(19.70 \pm 12.16$ vs $12.29 \pm 8.06$ days, $P<0.001)$, with no significant difference in intensive care unit-related mortality rates.

Conclusion: Combined administration of antibiotics, especially beta-lactam plus enzyme inhibitors and antifungals, may increase the incidence of AAD in critically ill patients.

Keywords: diarrhea, pseudomembranous colitis, intensive care units, antibiotics

\section{Introduction}

Antibiotic-associated diarrhea (AAD) is a syndrome characterized the disruption of intestinal flora as a result of antibiotic administration; furthermore, this diarrhea cannot otherwise be explained by other causes. ${ }^{1}$ It is a general term for a disorder of the intestinal flora with diarrhea as the main symptom. The incidence rate of AAD varies from $5 \%$ to $35 \%,{ }^{2,3}$ depending on demographics and antibiotic type. Generally, patients show symptoms as early as a few hours after antibiotic administration, and as late as 6-8 weeks after antibiotic discontinuation. Clostridium difficile (C.difficile) is the most common pathogenic bacterium. ${ }^{2,4-8}$ Among all patients with AAD, more than $20 \%$ experience initial treatment failure, and 
$40-60 \%$ experience a relapse. ${ }^{9,10}$ In recent years, with an increasing incidence rate, $\mathrm{AAD}$ has become an important disease related to nosocomial infection. Accordingly, the cost and length of hospital stay and the mortality rate are all rising. ${ }^{9,11-13}$ In patients admitted to the intensive care unit (ICU), the incidence rate of AAD is much higher, and the condition is more severe. ${ }^{14}$ Therefore, prevention of AAD is essential among critically ill patients.

A previous study suggested that almost all antibiotics can cause AAD. ${ }^{2}$ Risk factors for AAD include the type of antibiotic, use of a combination of antibiotics, and the length of hospital stay. ${ }^{13,15}$ However, past research focused mainly on the general population, and few studies have examined the risk factors for AAD in patients with critical conditions. Some authors ${ }^{4}$ have established that combined use of antibiotics leads to a significantly higher incidence rate of $\mathrm{AAD}$ among critically ill patients compared to antibiotic monotherapy. Due to the critical condition of ICU patients, antibiotics are more commonly used in combination with other drugs, than as monotherapy. Therefore, this study aimed to explore the difference in AAD incidence between antibiotic monotherapy and combined use of antibiotics among critically ill patients and to investigate further the type of antibiotics and combinations thereof that affect the incidence of AAD among critically ill patients.

\section{Methods}

\section{Patient cohort}

The population of interest comprised critically ill patients admitted to the ICU department of the First Affiliated Hospital of Xi'an Jiaotong University, from January 1, 2014 to December 31, 2015, in addition to patients receiving first-line antibiotic therapy. A total of 277 patients were enrolled (170 male, 107 female). Patients who used a combination of antibiotics were enrolled in the combined-use group, and those who used only one type of antibiotic were enrolled in the monotherapy group. The inclusion criteria were as follows: (1) patients receiving first-line antibiotic therapy during the study period and (2) antibiotic therapy lasting for more than 3 days. ${ }^{15}$ The exclusion criteria for patients were as follows: (1) no antibiotic administration, (2) multiple admissions to the ICU within 1 month, (3) a previous diagnosis of AAD within the preceding 3 months, (4) incomplete or missing case file data, and (5) diarrhea caused by other causes. The patient consent written informed consent, and this study was conducted in accordance with the Declaration of Helsinki. This study was reviewed and approved by the First Affiliated Hospital of Xi'an Jiaotong University Ethics committee (no. XJTU1AF2018LSK-097).

\section{Diagnosis of AAD}

AAD is defined as diarrhea associated with antibiotic exposure, either while on antibiotics or for up to 8 weeks after antibiotics have been discontinued. ${ }^{16}$ In clinical studies, diarrhea in adults is usually defined as $\geq 3$ liquid stools/d for at least 2 days. ${ }^{4,17}$ Symptoms can vary from mild selflimited disease to the more serious and severe Clostridium difficile associated diarrhea (CDAD). ${ }^{4,18}$

\section{Data collection}

Detailed records of the patient information and related data were collected. These included the name, sex, age, medical history, administration of parenteral nutrition, use of proton pump inhibitors, albumin levels, Acute Physiology and Chronic Health Evaluation (APACHE) II score upon ICU admission, type of antibiotic(s), occurrence of AAD, duration of ICU admission, and prognosis.

\section{Statistical analysis}

All relevant data were analyzed using SPSS version 18.0 (IBM Inc., Armonk, NY, USA). The data were expressed as the number of cases and relative percentages, and the correlation between groups was assessed using the chisquare test. Measurement data are expressed as the mean \pm standard deviation. After the data of all groups were tested for homogeneity of variance and normal distribution, independent sample $t$-tests were used to calculate the differences between the groups; significance was set at $P<0.05$. Univariate logistic regression analysis was performed for each variable, then, each variable with $P<0.05$ in the univariate analysis was included in the nonconditional logistic regression model. Independent risk factors were evaluated using multivariate analysis to determine AAD-related factors.

\section{Results}

\section{General information}

A total of 277 patients were enrolled, including 170 men and 107 women (average age: $52.78 \pm 21.47$ ). The total incidence of AAD was $31.05 \%$; AAD occurred mainly in patients who had used antibiotics for $6.96 \pm 4.28$ days. There were 143 patients in the combined-use group, including 95 men and 
48 women (average age: $53.91 \pm 21.14$ years). The monotherapy group comprised 134 patients, including 75 men and 59 women (average age: $51.57 \pm 21.82$ years). There were no significant differences between the two groups of patients in terms of age, sex, hypertensive state, prevalence of diabetes, the use of parenteral nutrition, use of proton pump inhibitors, albumin level, creatinine level, and APACHE II score at ICU admission $(P>0.05)$; this was indicative of good matching between the two groups. However, AAD incidence between the two groups was statistically significantly higher in the combined-use group than in the monotherapy group $(44.06 \%$ vs $17.16 \%, P<0.001)$ (Table 1$)$.

\section{The reason admission to ICU with patients receiving combined administration of antibiotics}

Out of the 143 patients receiving combined administration of antibiotics, there were $37(25.87 \%)$ cases of pulmonary disease or pneumonia, 31 (21.68\%) cases of sepsis, 21 (14.69\%) cases of multiple organ dysfunction syndrome (MODS), 16 (11.19\%) cases of surgery, 11 (7.69\%) cases of urinary disease, $7(4.89 \%)$ cases of heart disease, 6 $(4.20 \%)$ cases of organ transplantation, the 6 cases of organ transplantation had received organs from voluntary civilian organ donors, donated after cardiac death(DCD), 5 (3.50\%) cases of cardiopulmonary resusc, 9 (6.29\%) cases

Table I The clinic characteristics of the patients (mean \pm SD)

\begin{tabular}{|l|l|l|l|}
\hline Variables & $\begin{array}{l}\text { Single } \\
\text { antibiotics }\end{array}$ & $\begin{array}{l}\text { Combined } \\
\text { antibiotics }\end{array}$ & P-value \\
\hline No. of patients & 134 & 143 & \\
Age, years & $51.57 \pm 21.82$ & $53.91 \pm 21.14$ & 0.367 \\
Male: Female & 75.59 & $95: 48$ & 0.084 \\
Hypertension, $n(\%)$ & $36(26.87)$ & $39(27.27)$ & 0.939 \\
Diabetes, n (\%) & $15(11.19)$ & $16(11.19)$ & 0.999 \\
Parenteral nutrition, $n$ & $47(35.07)$ & $52(36.36)$ & 0.900 \\
(\%) & & & \\
Use proton pump & $121(90.30)$ & $128(89.51)$ & 0.845 \\
inhibitors, n (\%) & & & \\
Albumin levels (g/L) & $32.38 \pm 8.18$ & $30.90 \pm 6.84$ & 0.102 \\
APACHE II score at & $15.90 \pm 7.55$ & $17.54 \pm 7.18$ & 0.075 \\
admission to the ICU & & & \\
(points) & & & \\
Creatinine( $\mu$ mol/L) & 182.74 & 154.66 & 0.199 \\
& \pm 196.60 & \pm 166.04 & \\
AAD, n (\%) & $23(17.16)$ & $63(44.06)$ & $<0.001 *$ \\
\hline
\end{tabular}

Notes: *Two groups were significantly different, $P<0.05$.

Abbreviations: AAD, antibiotic-associated diarrhea; APACHE, Acute Physiology and Chronic Health Evaluation; ICU, intensive care unit.
Table 2 The reason admission to ICU with patients receiving combined administration of antibiotics

\begin{tabular}{|l|l|l|}
\hline Variables & $\mathbf{n}$ & $\%$ \\
\hline Pulmonary disease or pneumonia & 37 & 25.87 \\
Sepsis & 31 & 21.68 \\
Multiple organ dysfunction syndrome & 21 & 14.69 \\
Surgery & 16 & 11.19 \\
Urinary disease & 11 & 7.69 \\
Heart disease & 7 & 4.89 \\
Organ transplantation & 6 & 4.20 \\
Cardiopulmonary resusc & 5 & 3.50 \\
Other & 9 & 6.29 \\
Total & 143 & 100 \\
\hline
\end{tabular}

Abbreviation: ICU, intensive care unit.

of other diseases, including immune system diseases, digestive diseases, complex trauma, etc. (Table 2).

\section{Combination of antibiotics and AAD}

One hundred and forty-three patients $(51.62 \%)$ were treated with combined antibiotics. For critically ill patients in the ICU, the antibiotic combinations mainly comprised the following: two types of anti-Gram-negative bacteria antibiotics, combined with anti-Gram-positive bacteria antibiotics, combined with antifungal agents, combined with anti-anaerobic bacteria antibiotics, and a combination of three or more antibiotics. The total incidence of AAD was $44.06 \%$, of which, combined or sequential use of carbapenem antibiotics and beta-lactam plus enzyme inhibitor antibiotics led to the highest incident rate of AAD (56.52\%), followed by combined use of three or more antibiotics $(55.07 \%)$ and combined with antifungal agents $(50.49 \%)$. Table 3 describes statistical differences in AAD incidence among various combinations of antibiotic administration. (Table 3).

\section{Factors related to AAD in combined administration of antibiotics by univariate and multivariate regression analyses}

A univariate regression analysis of the risk factors associated with AAD showed that age, duration of proton pump inhibitor therapy, hypertension, antifungal antibiotics, and beta-lactam plus enzyme inhibitor antibiotics were associated with $\mathrm{AAD}$ in critically ill patients receiving combined antibiotic administration. However, albumin levels and APACHE II score at ICU admission, creatinine level, as well as parenteral nutrition, and the use of cephalosporins, carbapenems, quinolones, glycopeptides, and oxazolidinones was not associated with AAD in critically ill patients (Table 4). 
Table 3 Combination of antibiotics and AAD

\begin{tabular}{|c|c|c|c|}
\hline Variables & AAD & $\begin{array}{l}\text { NO } \\
\text { AAD }\end{array}$ & $\begin{array}{l}P \text { - } \\
\text { value }\end{array}$ \\
\hline No. of patients & 63 & 80 & \\
\hline $\begin{array}{l}\text { Combination use of three or } \\
\text { more antibiotics, } n(\%)^{a}\end{array}$ & $38(60.32)$ & $31(38.75)$ & 0.012 \\
\hline $\begin{array}{l}\text { Other antibiotics combined } \\
\text { with antifungals antibiotics, } n \\
(\%)^{\mathrm{b}}\end{array}$ & $52(82.54)$ & $51(63.75)$ & 0.015 \\
\hline $\begin{array}{l}\text { Other antibiotics combined } \\
\text { with anti-gram-positive bac- } \\
\text { teria antibiotics, } \mathrm{n}(\%)^{\mathrm{c}}\end{array}$ & $26(4 I .27)$ & $32(40.00)$ & 0.878 \\
\hline $\begin{array}{l}\text { Other antibiotics combined } \\
\text { with anti-anaerobic bacteria } \\
\text { antibiotics, } n(\%)^{d}\end{array}$ & $10(15.87)$ & $12(15.00)$ & 0.886 \\
\hline $\begin{array}{l}\text { Other antibiotics combined } \\
\text { with azithromycin, } \mathrm{n}(\%)\end{array}$ & $3(4.76)$ & II (13.75) & 0.092 \\
\hline $\begin{array}{l}\text { Combined or sequential use } \\
\text { of carbapenem antibiotics and } \\
\text { beta-lactam plus enzyme inhi- } \\
\text { bitors antibiotics, } n(\%)^{\mathrm{e}}\end{array}$ & $26(4 \mid .27)$ & $20(25.00)$ & 0.048 \\
\hline
\end{tabular}

Notes: Other antibiotics include one or more of the following antibiotics: Carbapenem, Betalactam plus enzyme inhibitor antibiotics, Antifungals, Cephalosporins, Quinolones, Glycopeptides, Oxazolidinones, Anti-anaerobic bacteria Antibiotics, Azithromycins. ${ }^{a}$ Compare for Combination use of three or more antibiotics and Combination use of two antibiotics. ${ }^{b}$ Antifungals antibiotics were azoles and echinocanins. 'Anti-Grampositive bacteria antibiotics were glycopeptides (Vancomycin, teicoplanin), Oxazolidinones (Linezolid). ${ }^{\mathrm{d} A n t i-a n a e r o b i c ~ b a c t e r i a ~ a n t i b i o t i c s ~ w e r e ~ m e t r o n i d a z o l e . ~}$ ${ }^{\text {e}}$ The beta-lactam plus enzyme inhibitor antibiotics were piperacillin-tazobactam and sulbactam-cefoperazone.

Abbreviation: AAD, antibiotic-associated diarrhea.

The risk factors that were associated with AAD in critically ill patients with combined administration of antibiotics even after the multivariate regression analysis were duration of proton pump inhibitor therapy (odds ratio [OR] 1.142, 95\% confidence interval $[\mathrm{CI}] 1.048-1.244, P=0.002)$, antifungal antibiotics (OR 3.189, 95\% CI 1.314-7.740, $P=0.010$ ), beta-lactam plus enzyme inhibitor antibiotics (OR 3.072, 95\% CI 1.309-7.205, $P=0.010$ ) (Table 4).

Use of carbapenems or beta-lactam plus enzyme inhibitor antibiotics and AAD

Of the 277 patients enrolled, 237 received antibiotic monotherapy or combined or sequential use of either carbapenems or beta-lactam plus enzyme inhibitor antibiotics; the overall incidence of AAD was $34.60 \%$. Forty-six patients (19.41\%) were administered combined or sequential use of carbapenem antibiotics and beta-lactam plus enzyme inhibitor antibiotics, 28 patients (11.81\%) received carbapenem antibiotics alone, 79 patients (33.34\%) received beta-lactam plus enzyme inhibitor antibiotics alone, 28 patients (11.81\%) received a carbapenem antibiotic-based combination, and 56 patients (23.63\%) received a beta-lactam plus enzyme inhibitor antibioticbased combination (Table 5).

The incidence of AAD was statistically significant $(p<0.05)$ when the combined or sequential use of carbapenem antibiotics and beta-lactam plus enzyme inhibitor antibiotics was compared with the use of carbapenem antibiotics alone, beta-lactam plus enzyme inhibitor antibiotics alone, and a carbapenem antibiotic-based combination. The incidence of AAD was statistically significant $(p<0.05)$ when the use of beta-lactam plus enzyme inhibitor antibiotics alone was compared with the use of carbapenem antibiotics alone. The incidence of AAD was statistically significant $(p<0.05)$ when use of a betalactam plus enzyme inhibitor antibiotic-based combination was compared with the use of carbapenem antibiotics alone or the use of beta-lactam plus enzyme inhibitor antibiotics alone. There were no statistically significant differences $(P>0.05)$ in the incidence of AAD between carbapenem antibiotic-based combinations and carbapenem antibiotics alone, beta-lactam plus enzyme inhibitor antibiotic-based combinations, and combined, or sequential use of carbapenem antibiotics and beta-lactam plus enzyme inhibitor antibiotics (Table 5).

\section{Outcome evaluation}

Out of the 143 patients receiving combined administration of antibiotics, 16 died (AAD 6, no AAD 10). There was no significant difference in mortality in the ICU between the two groups $(P=0.607)$. AAD did not directly cause any deaths in either group. Duration of ICU admission was statistically longer among patients with $\mathrm{AAD}$, compared to those without AAD $(19.70 \pm 12.16$ vs $12.29 \pm 8.06$ days, $P<0.001)$. (Table 6 ).

\section{Discussion}

With the extensive use of antibiotics, the incidence of AAD has increased annually and has become the most common intestinal infectious disease. ${ }^{19,20}$ More than $90 \%$ of the intestinal bacteria are Bacteroides. ${ }^{2}$ After the application of antimicrobial drugs, most of the sensitive bacterial species in the intestinal tract are inhibited, and the resistant bacteria subsequently reproduce. For example, C. difficile becomes the dominant bacterial population, producing toxins $\mathrm{A}$ and $\mathrm{B}$, thus causing diarrhea, thereby inducing $\mathrm{AAD}^{2,21}$ The main clinical manifestations of AAD are diarrhea, mainly as watery stool, although there may be mucus, pus, or blood in the stool; increased white blood cell count; fever; abdominal pain; abdominal distension; toxic megacolon; and multiple organ dysfunction, 
Table 4 Factors related to AAD in combined administration of antibiotics by univariate and multivariate regression analyses

\begin{tabular}{|c|c|c|c|c|}
\hline \multirow[t]{2}{*}{ Related factors } & \multicolumn{2}{|c|}{ Univariate regression analysis } & \multicolumn{2}{|c|}{ Multivariate regression analysis } \\
\hline & OR $(95 \% \mathrm{Cl})$ & $P$-value & OR $(95 \% \mathrm{CI})$ & $P$-value \\
\hline Age & $1.019(1.002-1.035)$ & 0.026 & $1.009(0.989-1.029)$ & 0.380 \\
\hline Male & $1.712(0.837-3.501)$ & 0.141 & & \\
\hline Use proton pump inhibitors & $2.830(0.915-8.758)$ & 0.071 & & \\
\hline Proton pump inhibitors time & $1.127(1.043-1.218)$ & 0.003 & $1.142(1.048-1.244)$ & 0.002 \\
\hline Parenteral nutrition & $1.650(0.830-3.28 I)$ & 0.153 & & \\
\hline Preventive use of probiotics & $0.802(0.395-1.627)$ & 0.541 & & \\
\hline Albumin levels & $1.023(0.975-1.073)$ & 0.352 & & \\
\hline Hypertension & $2.667(1.250-5.688)$ & 0.011 & $1.799(0.719-4.500)$ & 0.209 \\
\hline Diabetes & $1.014(0.356-2.892)$ & 0.979 & & \\
\hline APACHE II score at admission into the ICU & $1.014(0.967-1.065)$ & 0.562 & & \\
\hline Creatinine & $1.000(0.998-1.002)$ & 0.683 & & \\
\hline Antifungals & $2.688(1.215-5.948)$ & 0.015 & $3.189(1.314-7.740)$ & 0.010 \\
\hline Cephalosporins & $1.213(0.583-2.525)$ & 0.605 & & \\
\hline Carbapenem & $1.076(0.554-2.088)$ & 0.830 & & \\
\hline Beta-lactam plus enzyme inhibitors ${ }^{a}$ & $2.836(1.284-6.265)$ & 0.010 & $3.072(1.309-7.205)$ & 0.010 \\
\hline Quinolones & $1.886(0.852-4.174)$ & 0.118 & & \\
\hline Glycopeptides $^{b}$ & $1.273(0.512-3.166)$ & 0.604 & & \\
\hline Oxazolidinones & $1.622(0.800-3.289)$ & 0.180 & & \\
\hline Anti-anaerobic bacteria Antibiotics ${ }^{c}$ & $1.069(0.429-2.664)$ & 0.886 & & \\
\hline Azithromycins & $2.603(0.797-8.506)$ & 0.113 & & \\
\hline
\end{tabular}

Notes: ${ }^{a}$ Beta-lactam plus enzyme inhibitors were piperacillin-tazobactam and sulbactam-cefoperazone. ${ }^{b}$ Glycopeptides were Vancomycin and teicoplanin. ${ }^{\mathrm{C}}$ Anti-anaerobic bacteria antibiotics were metronidazole.

Abbreviation: AAD, antibiotic-associated diarrhea.

Table 5 Use of carbapenems or beta-lactam plus enzyme inhibitor antibiotics and $A A D$

\begin{tabular}{|c|c|c|c|}
\hline Variables & AAD & $\begin{array}{l}\text { NO } \\
\text { AAD }\end{array}$ & $P$-value \\
\hline No. of patients & 82 & 155 & \\
\hline $\begin{array}{l}\text { Combined or sequential } \\
\text { use of carbapenem anti- } \\
\text { biotics and beta-lactam } \\
\text { plus enzyme inhibitors } \\
\text { antibiotics, } \mathrm{n}(\%)^{\mathrm{a}}\end{array}$ & $26(31.7 I)$ & $20(12.90)$ & $<0.00 I^{*}$ \\
\hline $\begin{array}{l}\text { Carbapenem antibiotics } \\
\text { alone, } \mathrm{n}(\%)^{\mathrm{b}}\end{array}$ & $2(2.44)$ & $26(16.78)$ & $0.077^{\#}$ \\
\hline $\begin{array}{l}\text { Beta-lactam plus enzyme } \\
\text { inhibitors antibiotics } \\
\text { alone, } n(\%)^{c}\end{array}$ & $19(23.17)$ & $60(38.71)$ & $0.042 * *$ \\
\hline $\begin{array}{l}\text { Carbapenem antibiotics- } \\
\text { based combination, } \mathrm{n}(\%)^{\mathrm{d}}\end{array}$ & $8(9.76)$ & $20(12.90)$ & $0.061^{\# \#}$ \\
\hline $\begin{array}{l}\text { Beta-lactam plus enzyme } \\
\text { inhibitors antibiotics - } \\
\text { based combination, n (\%) }\end{array}$ & $27(32.92)$ & $29(|8.7|)$ & $<0.001 * * *$ \\
\hline
\end{tabular}

Notes: *Compare for a and $b, a$ and $c, P<0.001$; Compare for a and $d, P=0.01$. **Compare for c and b. *** Compare for e and b, $P<0.001$; Compare for e and c, $P=0.002$. "Compare for $b$ and $d .{ }^{\#}$ Compare for $d$ and e.

Abbreviation: AAD, antibiotic-associated diarrhea.
Table 6 The outcome of patients receiving combined administration of antibiotics

\begin{tabular}{|l|l|l|l|}
\hline Variables & AAD & $\begin{array}{l}\text { No } \\
\text { AAD }\end{array}$ & $\begin{array}{l}\boldsymbol{P} \text { - } \\
\text { value }\end{array}$ \\
\hline No. of patients & 63 & 80 & \\
ICU stay time, days, mean & 19.70 & 12.29 & $<0.001$ \\
\pm SD & \pm 12.16 & \pm 8.06 & \\
ICU mortality, n (\%) & $6(9.52)$ & $10(12.50)$ & 0.607 \\
\hline
\end{tabular}

Abbreviations: $A A D$, antibiotic-associated diarrhea; ICU, intensive care unit.

among other symptoms. A characteristic of the disease is the appearance of a large amount of intestinal pseudomembranous mucosa floating on the watery stools.

At present, it is believed that the main cause of AAD is the abuse of antibiotics, especially broad-spectrum antibiotics. $^{22}$ Our research showed that beta-lactam plus enzyme inhibitor antibiotics were more likely to cause AAD in critically ill patients compared with carbapenem antibiotics. ${ }^{23}$ This may be related to the following reasons: The main reason for the difference in the use of antibiotics is related to how clinicians select antibiotics. Conversely, 
the study was limited by a relatively small sample size. A larger sample will be needed to confirm this in the future. However, it is useful to realize that the use of betalactam plus enzyme inhibitor antibiotics may increase the risk of AAD occurrence in critically ill patients.

Studies among the general population have shown that exposure to antibiotics is a risk factor for the development of AAD, especially when 2 or more antibiotics are used together, ${ }^{22}$ with a course of more than 3 days. Additionally, the length of hospital stay and the duration of exposure to the antibiotics are all risk factors for AAD. ${ }^{13,15}$ Our research on critically ill patients also found that the combined use of antibiotics is more likely to induce AAD than antibiotic monotherapy, which is consistent with the results of the current study. ${ }^{13,15}$ The occurrence of AAD in critically ill patients was noted after an average of $6.96 \pm 4.28$ days posttreatment initiation, especially among those who were treated with combination antibiotics therapy; the shortest time until the appearance of AAD was approximately $24 \mathrm{hrs}$. Patients in the ICU are in critical condition, and it is difficult to discontinue administration of these relevant antibiotics, even if $\mathrm{AAD}$ appears.

Current research ${ }^{4}$ suggests that combined use of antibiotics is more likely to cause AAD. For critically ill patients in the ICU, combined antibiotic administration is used for treatment due to both the complexity of the condition and the severity of infection. We found that antibiotics are combined in the ICU in a number of ways, namely: a combination of two or more antibiotics, combined use of antifungal antibiotics, combined use of anti-gram-positive bacteria antibiotics, and combined use of anti-anaerobic bacteria antibiotics, among others. By comparison, we found that a combination of three or more antibiotics is more likely to cause AAD than a combination of two antibiotics. A possible explanation thereof could be the increased likelihood of intestinal flora disruption when a combination of antibiotics is administered, resulting in the increased drug-resistant bacteria, such as $C$. difficile, leading to AAD. We also found that critically ill patients receiving combination therapy including antifungal agents were more likely to develop AAD; this risk factor for AAD has not been reported in the literature, and the condition of these patients may be more severe than previously thought. Furthermore, for those with confirmed, or suspected fungal infections, immunity may be weakened, making them prone to developing AAD. Of course, antifungal agents may also be associated with an earlier disturbance of the intestinal flora, resulting in an increased incidence of AAD.
There were no statistically significant differences in the occurrence of AAD among critically ill patients when comparing those administered with combination and non-combination anti-anaerobe antibiotics, and between combination and non-combination antibiotics against Gram-positive bacterial species. To our knowledge, this has not been reported earlier in the literature. In previous studies, ${ }^{2,4,24,25}$ the incidence of AAD was highest among patients who had used azithromycin; we found no statistically significant difference. A possible explanation for this may be the small sample size used in this study. Thus, a larger sample is warranted for further research.

We found that AAD was more likely to occur in patients who were either simultaneously administered carbapenems and beta-lactam plus enzyme inhibitor antibiotics, or in those who underwent sequential administration of both, or carbapenem monotherapy, beta-lactam plus enzyme inhibitor monotherapy, or combinations including carbapenems. $\mathrm{AAD}$ is more likely to occur when there is administration of combinations antibiotic therapy (including beta-lactam plus enzyme inhibitor antibiotics) than in carbapenem or betalactam plus enzyme inhibitor monotherapy. Combined use of beta-lactam plus enzyme inhibitors is a risk factor for AAD.. ${ }^{23}$ Therefore, combinations including beta-lactam plus enzyme inhibitor antibiotics in critically ill patients may be more likely to cause AAD and may be even more dangerous than combinations including carbapenems.

It has been reported ${ }^{26}$ that both the use of proton pump inhibitors and hypoproteinemia are associated with AAD and that in particular, there is a significant correlation with the recurrence of $C$. difficile colitis. In this study, there was also no significant difference with the use of proton pump inhibitors or albumin levels in relation to AAD occurrence This is suggestive of a small sample size; therefore the combined use of proton pump inhibitors in 128 of the 143 combined antibiotics in this study, resulted in a smaller number of patients not receiving proton pump inhibitor therapy. A related study on proton pump inhibitors ${ }^{27}$ indicated that the risk of $C$. difficile infection in the hospital was positively correlated with proton pump inhibitor dosage. Patients with $C$. difficile infection are administered proton pump inhibitors during anti-infective treatment; the risk of re-infection with $C$. difficile is significantly increased as a result thereof. Our study found that the duration of proton pump inhibitor therapy was positively correlated with the occurrence of AAD in critically ill patients receiving combined administration of antibiotics, 
which is consistent with the literature. Our study found that creatinine was not associated with AAD in critically ill patients receiving combined administration of antibiotics; more relevant studies are further warranted.

The duration of ICU admission was found to be significantly lower in the no AAD group, indicating that the occurrence of AAD could prolong the duration of ICU admission of critically ill patients. However, there was no significant difference in mortality between the two groups mentioned earlier, which is not consistent with previous reports. Some patients did not improve or die when they were discharged because of customs, family factors, etc., and as such, cannot be classified into either the "survival" or "death" statistics; this might be the main cause of the difference in mortality reported in the literature.

\section{Conclusion}

Combined use of antibiotics is directly related to the occurrence of $\mathrm{AAD}$ in critically ill patients, especially with the combined use of three or more antibiotics. Concurrently, further studies have shown that combinations including antifungal agents, simultaneous use of carbapenems and beta-lactam plus enzyme inhibitor antibiotics (or sequential use of both antibiotics), and combinations including betalactam plus enzyme inhibitor antibiotics increased the occurrence of AAD among critically ill patients. Durations of proton pump inhibitor therapy, antifungal antibiotics, and beta-lactam plus enzyme inhibitor antibiotics are associated with $\mathrm{AAD}$ in critically ill patients receiving combined administration of antibiotics. In addition, the duration of ICU admission was significantly longer in critically ill patients after AAD. Therefore, in order to prevent the occurrence of AAD in critically ill patients, strict control of the indications of antibiotic use is recommended in clinical treatment, and combinations of antibiotics should be avoided as much as possible. As for the association between the combination of antibiotics and the incidence of AAD in critically ill patients, more relevant studies are needed in order to better guide clinical treatment.

\section{Ethical approval}

This study was reviewed and approved by The First Affiliated Hospital of Xi'an Jiaotong University Ethics committee (No. XJTU1AF2018LSK-097).

\section{Acknowledgments}

This study was supported by the Clinical Research Award of the First Affiliated Hospital of Xi'an Jiaotong
University, China (No. XJTU1AF-CRF-2018-011); and the Institutional Foundation of the First Affiliated Hospital of Xi'an Jiaotong University (2018MS-11).

\section{Disclosure}

The authors report no conflicts of interest in this work.

\section{References}

1. Bartlett JG. Antibiotic associated diarrhea. $N$ Engl J Med. 2002;346 (5):334-339. doi:10.1056/NEJMcp011603

2. Tian CF, Su BY, Li YJ, et al. Management of antibiotic-associated pseudomembranous colitis in Non-hospitalized and hospitalized patients. Pak J Pharm Sci. 2016;29(5(Suppl)):1805-1810.

3. Huang $\mathrm{H}$, Wu S, Wang M, et al. Molecular and clinical characteristics of clostridium difficile infection in an university hospital in Shanghai, China. Clin Infect Dis. 2008;47(12):1606-1608. doi:10.1086/596321

4. Surawicz CM, Brandt LJ, Binion DG, et al. Guidelines for diagnosis, treatment,and prevention of clostridium difficile infections. Am J Gastroenterol. 2013;108(4):478-498. doi:10.1038/ajg.2013.4

5. Plummer S, Weaver MA, Harris JC, Dee P, Hunter J. Clostridium difficile pilot study: effectsof probiotic supplementation on the incidence of C.difficile diarrhoea. Int Microbiol. 2004;7:59-62.

6. Schroeder MS. Clostridium difficile-associated diarrhea. Am Fam Physician. 2005;71:921-928.

7. Giannelli FR. Antibiotic-associated diarrhea. JAAPA. 2017;30 (10):46-47. doi:10.1097/01.JAA.0000524721.01579.c9

8. Blaabjerg S, Artzi DM, Aabenhus R. Probiotics for the prevention of antibiotic-associated diarrhea in outpatients-a systematic review and meta-analysis. Antibiotics. 2017;6(4):21-37. doi:10.3390/ antibiotics6040021

9. Shen NT, Maw A, Tmanova LL, et al. Timely use of probiotics in hospitalized adults prevents clostridium difficile infection: a systematic review with meta-regression analysis. Gastroenterology. 2017;152(8):1889-1900. doi:10.1053/j.gastro.2017.02.003

10. Kelly CP. A 76-year-old man with recurrent clostridium difficileassociated diarrhea: review of Clostridium difficile infection. JAMA. 2009;301:954-962. doi:10.1001/jama.2009.171

11. Mejia-Chew C, Dubberke ER. Clostridium difficile control measures: currentand future methods for prevention. Expert Rev Anti Infect Ther. 2018;16(2):121-131. doi:10.1080/14787210.2018.1429911

12. Hempel S, Newberry SJ, Maher AR, et al. Probiotics for the prevention and treatment of antibiotic-associated diarrhea: asystematic review and meta-analysis. JAMA. 2012;307(18):1959-1969. doi:10.1001/jama.2012.3507

13. Ruiter-Ligeti J, Vincent S, Czuzoj-Shulman N, Abenhaim HA. Risk factors, incidence, and morbidity associated with obstetric clostridium difficile infection. Obstet Gynecol. 2018;131(2):387-391. doi:10.1097/AOG.0000000000002422

14. Oughton MT, Miller MA. Clinical and epidemiological aspects of Clostridium diffcile. Clin Microbiol Newsl. 2008;30(12):87-95. doi:10.1016/j.clinmicnews.2008.05.004

15. Videlock EJ, Cremonini F. Meta-analysis: probioticsin antibiotic-associated diarrhea. Aliment Pharmacol Ther. 2012;35 (12):1355-1369. doi:10.1111/j.1365-2036.2012.05104.x

16. Vernice MFL, Metehan O, Cagri DE, et al. Comparison of pediatric and adult antibiotic-associated diarrhea and $\backslash \mathrm{r}$, Clostridium difficile $\backslash \mathrm{r}$, infections. World J Gastroenterol. 2016;22(11):3078-3104. doi:10.3748/wjg.v22.i11.3078

17. Khanna S, Pardi DS, Aronson SL, et al. The epidemiology of community-acquired clostridium difficile infection: a population-based study. Am J Gastroenterol. 2012;107(1):89-95. doi:10.1038/ajg.2011.398 
18. Debast SB, Bauer MP, Kuijper EJ. European society of clinical microbiology and infectious diseases: update of the treatment guidance document for clostridium difficile infection. Clin Microbiol Infec. 2014;20(s2):1-26. doi:10.1111/1469-0691.12418

19. Lau CS, Chamberlain RS. Probiotics are effective at preventing clostridium difficile-associated diarrhea: asystematic review and meta-analysis. Int J Gen Med. 2016;9:27-37. doi:10.2147/IJGM.S98280

20. Yoldas O, Altindis M, Cufali D, Aşık G, Keşli R. A diagnostic algorithm for the detection of clostridium difficile-associated diarrhea. Balkan Med J. 2016;33(1):80-86. doi:10.5152/balkanmedj.2015.15159

21. Roberts T, Kokaikun JF, Coughlin O, et al. Tolerability and pharmacokinetics of SYN-004,an orally administered $\beta$-lactamase for the prevention of clostridium difficile-associated disease and antibioticassociated diarrhea,in two phase 1 studies. Clin Drug Investig. 2016;36(9):725-734. doi:10.1007/s40261-016-0420-0

22. Viswanathan VK, Mallozzi MJ, Vedantam G. Clostridium difficile infection: anoverview of the disease and its pathogenesis,epidemiology and interventions. Gut Microbes. 2010;1(4):234-242. doi:10.4161/gmic.1.4.12706
23. Zhang Y, Sun J, Zhang J, Liu Y, Guo L. Beta-lactam plus enzyme inhibitor antibiotics and antibiotic-associated diarrhea in critically Ill patients. Med Sci Monit. 2018;24:8781-8788. doi:10.12659/ MSM.913739

24. Owens RC, Donskey CJ, Gaynes RP, Loo VG, Muto CA. Antimicrobial-associated risk factors for clostridium difficile infection. Clin Infect Dis. 2008;46(1):S19-S31. doi:10.1086/521859

25. Bauer MP, van Dissel JT. Alternative strategies for clostridium difficile infection. Int $J$ Antimicrob Agents. 2009;33(1):S51-S56. doi:10.1016/S0924-8579(09)70018-4

26. Rotramel A, Poritz LS, Messaris E, Berg A, Stewart DB. PPI therapy and albumin are better predictors of recurrent clostridium difficile colitis than choice of antibiotics. Gastrointest Surg. 2012;16:2267-2273. doi:10.1007/s11605-012-2037-9

27. Howell MD, Novack V, Grgurich P, et al. Iatrogenic gastric acid suppression and the risk of nosocomial clostridium difficile infection. Arch Intern Med. 2010;170(9):784-790. doi:10.1001/ archinternmed.2010.89

\section{Publish your work in this journal}

Infection and Drug Resistance is an international, peer-reviewed openaccess journal that focuses on the optimal treatment of infection (bacterial, fungal and viral) and the development and institution of preventive strategies to minimize the development and spread of resistance. The journal is specifically concerned with the epidemiology of antibiotic resistance and the mechanisms of resistance development and diffusion in both hospitals and the community. The manuscript management system is completely online and includes a very quick and fair peerreview system, which is all easy to use. Visit http://www.dovepress.com testimonials.php to read real quotes from published authors. 